\title{
INUNDACIONES HISTÓRICAS Y DESERTIFICACION EN EL SECTOR CENTRAL DE LA VERTIENTE SURMEDITERRÁNEA ANDALUZA (MÁLAGA Y GRANADA) ${ }^{1}$
}

\author{
Francisco de Asís Rodríguez Martínez \\ Instituto de Desarrollo Regional. Universidad de Granada \\ Miguel Ángel Mesa Garrido \\ Instituto de Desarrollo Regional. Universidad de Granada. Coordinador de Unidad \\ Biogeográfica. Espacio Natural de Sierra Nevada. Consejería de Medio Ambiente y \\ Ordenación del Territorio
}

\section{RESUMEN}

Este trabajo desarrolla una aproximación, a escala subregional, al problema de las inundaciones históricas mediterráneas, sin perder de vista la globalidad del mismo y su traducción en términos de desertificación. Se pone especial énfasis en el origen del problema y su corrección mediante la política forestal de restauración hidrológica. Para ello se sirven los autores de trabajos de campo y la utilización de fuentes nuevas o poco usadas hasta el momento, como los archivos nacionales y locales y la revista Montes.

Palabras clave: torrencialidad, inundaciones, montes públicos, sur de España

\section{ABSTRACT}

Historic floods and desertification in the central sector of the andalusian southern Mediterranean watershed (Malaga and Granada)

This work develops an approach of the problem of Mediterranean historic floods and its effects on desertification at the sub-regional scale. It focuses on the root of the problem and the hidrological forestry correction policies. Archivist and unusual bibliographical sources are used in addition to field work.

Keywords: Torrentiality, Flooding, Public Forest, Southern Spain

1. El presente trabajo se enmarca en un estudio más amplio sobre el tema, objeto una tesis doctoral a punto de concluirse con el título «Geografía y política forestal. Una visión integrada de la gestión de los montes en la provincia de Granada (Siglos XVIII-XX)». 
La vertiente sur española afecta a las provincias andaluzas de Huelva, Sevilla, Cádiz, Málaga, Granada y Almería. Se divide administrativamente en dos sectores, el atlántico, que comprende las subcuencas Guadalete-Barbate y Tinto-Odiel y Guadiana, y el mediterráneo que incluye las subcuencas de los ríos, ríos-rambla y ramblas que desembocan en este mar en las provincias de Málaga, Granada y Almería, principalmente las del Guadiaro, Guadalhorce, Guadalmedina, Vélez, Guadalfeo, Grande de Adra, Andarax y Almanzora. La extensión superficial de las cuencas vertientes es muy variable, oscilando entre $7.500 \mathrm{Km}^{2}$ en la provincia de Almería, $2.638 \mathrm{Km}^{2}$ en la provincia de Granada y $6.831 \mathrm{~km}^{2}$ en la provincia de Málaga. En conjunto la vertiente surmediterránea, denominada erróneamente cuenca sur, viene a suponer un $20 \%$ de la superficie total de Andalucía y el 71\% de la superficie de la vertiente sur. Nuestra área de estudio en las provincias de Málaga y Granada (Figura 1) comprende $9.470 \mathrm{Km}^{2}$, algo más del $56 \%$ de la extensión total de la vertiente surmediterránea. La presencia en esta área de dos alineaciones montañosas, litoral y prelitoral, integradas casi por completo en el dominio interno de las cordilleras Béticas, paralelas y muy próximas al mar Mediterráneo, con las mayores cumbres de la Península y una elevada altitud media, genera una red hidrográfica especialmente densa y compleja en la que abundan cursos de agua (más de cien), permanentes y esporádicos, muy irregulares siempre en su régimen hídrico anual e interanual ya que además de una pluviometría que oscila entre árido y subhúmedo, discurren sobre terrenos antiguos compuestos en gran medida por materiales muy deleznables, como los micasquistos y las filitas, o bien compactos cristalinos, intensamente meteorizados como las calizo-dolomías primarias ${ }^{2}$.

\section{INUNDACIONES Y RESTAURACIÓN HIDROLÓGICO-FORESTAL EN LA VERTIENTE SURMEDITERRÁNEA}

Las inundaciones eran y son todavía en gran medida un problema generalizado en el área mediterránea española, como también en muchos otros países. Las causas son diversas, tanto las de tipo natural, como las de tipo antrópico, relacionadas con la deforestación de los montes principalmente y con la situación de las infraestructuras urbanas y agrarias, aunque en muchos casos se suman los dos factores. Por su parte, nuestro ámbito de estudio se caracteriza por tener una incidencia secular de inundaciones que provocaron numerosas pérdidas materiales y humanas a lo largo del tiempo. En este ámbito surmediterráneo, las inundaciones se produjeron de forma continuada principalmente en algunas de las cuencas como las del Guadalmedina, o Guadalhorce, Guadalfeo, Rambla de

2. Rodríguez Martínez, F.: « Los derrames penibéticos» En Gil Olcina, A.(coord.): Alteraciones de los regímenes hídricos peninsulares, 1.901-2.001. 
Figura 1: Localización de la zona de estudio en relación a la Vertiente Sur Andaluza y Surmediterránea

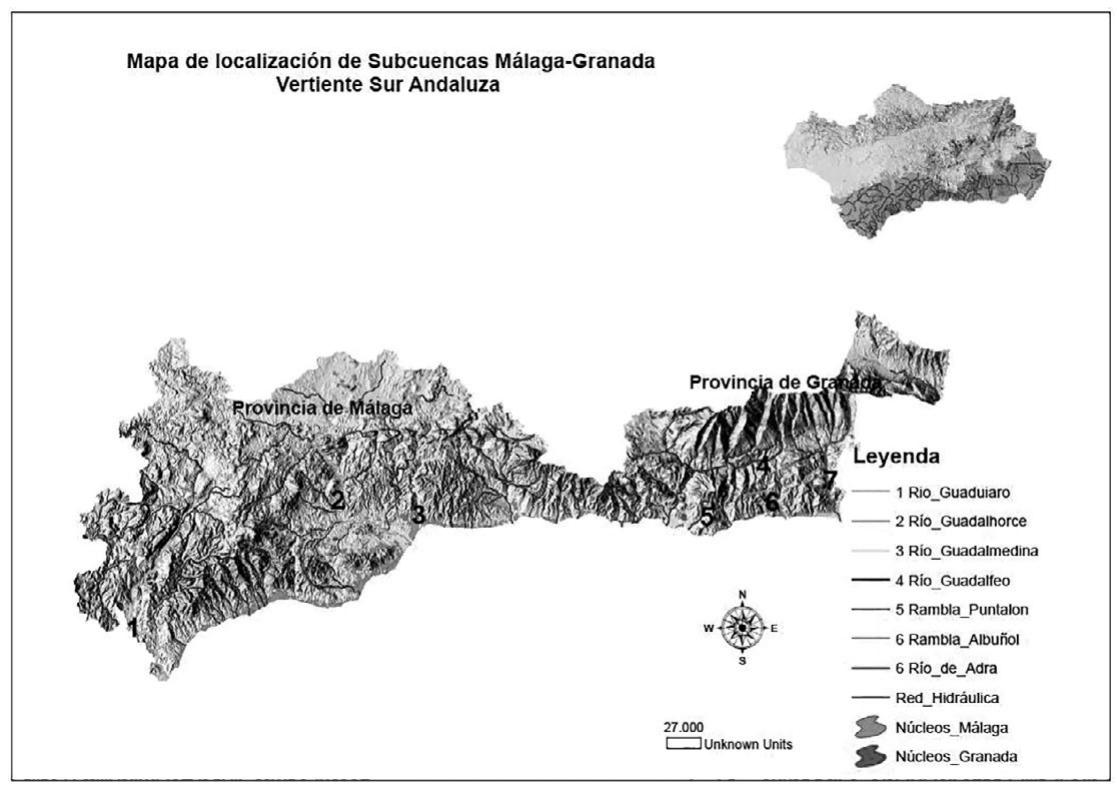

Fuente: Elaboración propia a partir de distintas fuentes.

Albuñol, Adra, Andarax, Almanzora etc que causaron de forma repetida daños materiales y pérdida de vidas humanas.

Si bien tiene relevancia el área de estudio por la intensidad y frecuencia ${ }^{3}$ con que se producen los episodios de avenidas e inundaciones, su mayor importancia radica, sin embargo, en la existencia de un importante elenco de bienes materiales que se ven afectados por los mismos. Destacan en este sentido, en primer lugar, un importante hábitat costero donde destacan las ciudades como Málaga, Motril, Salobreña, Adra, Almería...en donde las avenidas catastróficas se dejan sentir especialmente. Pero, asimismo, en segundo lugar, destaca tanto la generación, producto también de las avenidas, de numerosas vegas aluviales, conos de deyección y deltas, ocupados y transformados progresivamente por el hombre sin proveerse siempre de los medios técnicos de defensa, muy variables según las circunstancias económicas y la tecnología disponible

Las inundaciones vienen produciéndose en la vertiente surmediterránea desde tiempo inmemorial y han quedado constatadas a lo largo del tiempo en numerosos estudios geográficos, históricos y de otras disciplinas sobre todo la 
Ingeniería de Montes ${ }^{4}$. En este caso concreto por su relación directa con la deforestación de los montes, lo que ha determinado una importante intervención en el marco de los Montes Protectores que se recogía ya en la Ley de Repoblación Forestal de $1.808^{5}$. Sin embargo, este tema no se ha tratado suficientemente desde una perspectiva global e integradora que recogiera la relación de las inundaciones con la erosión del suelo, la torrencialidad y la desertificación y sus consecuencias en el territorio y, sobre todo, las intervenciones forestales que se han llevado a cabo con el fin de paliar el problema por parte de la Administración Forestal. Por ello haremos aquí especial referencia a ello.

Como ya se ha apuntado las consecuencias de las inundaciones han sido catastróficas muchas veces, provocando pérdidas ${ }^{6}$ de gran importancia y magnitud a lo largo de la historia. En nuestra área de estudio los ríos o ramblas aunque cortos salvan las mayores pendientes y desniveles de la Península. Este aspecto se ve agravado por la peculiar climatología de las cuencas de recepción en alta y media montaña que determinan la alta concentración horaria de la precipitación y un desagüe inmediato, elementos esenciales de la torrencialidad. Los excepcionales episodios de lluvias intensas prolongados durante días se produjeron en varios periodos pudiéndose identificar, en el marco indicado por MARTín y OlCINA, referencias surmediterráneas a las cuatro oscilaciones de sucesos catastróficos, precipitaciones intensas, grandes nevadas y temporales de mar, señaladas para España, una a mediados del siglo XV y otras tres centradas, respectivamente, en 1510-1610, 1760-1800 y 1829-1860. En el mismo sentido, el periodo final de

4. Podemos citar como ejemplos algunos trabajos, entre ellos, los de Gómez Mendoza, J. y Ortega Cantero, "Inundaciones históricas y la génesis de la acción hidrológico-forestal en España (1.885-1933)».1989, Gil Olcina, A y Morales Gil, A: Avenidas fluviales en la cuenca del Mediterráneo. Alicante, Instituto Universitario de Geografía. Planificación hidráulica en España. Alicante. Fundación Cultural de la caja de Ahorros del Mediterráneo, Editores 1995.; Demanda y economía del agua en España. Fundación Cultural de la caja de Ahorros del Mediterráneo 1988. Lluvias excepcionales en la noche del 19 al 21 de octubre de 1982 y riada del Barranco de las Ovejas, lluvias torrenciales e inundaciones en Alicante. Servicio de Publicaciones de la Universidad de Alicante, 1983. Alteraciones de los Regímenes fluviales y peninsulares.; Actuaciones pioneras para riego y defensa contra avenidas en los ríos-rambla surestinos. Olcina Cantos, J. Riesgos fluviales y ordenación del territorio. Olcina Cantos, J. Evolución y distribución territorial de las demandas de agua para uso agrícola y su incidencia en el régimen de los ríos... Inundaciones en la ciudad y término de Alicante, Alicante, Universidad de Alicante. Gil Olcina A., Morales Gil, A., Bru Ronda, C. Marco Molina J.A. 1986.

5. Mesa GarRido. M.A. (2015): «La política de los montes protectores y su relación con los riesgos naturales en la provincia de Granada». Cuadernos Geográficos de la Universidad de Granada, n. ${ }^{\circ}$ 54-1.

6. Según Martín y Olcina (2001) Las pérdidas por los sucesos atmosféricos, riesgos climatológicos en España, se producen pérdidas que ascendían en 2.001 a 100.000 millones de pesetas cada año, además de los años en los que se han producido grandes episodios de inundación como 1989, 1995, 1997, 2000 o las sequias de 1992, 1993, 1994 y 1995 multiplica por tres o cuatro esta cifra. 
la Pequeña Edad de Hielo se caracterizó por periodos de lluvias intensas que alternaban con periodos de sequía, como queda constatado en los cambios de los humedales meridionales de Doñana (Sousa, A. y García Murillo, P., 2.003 citan a Barrientos y Martín-Vide (1998) y RodRIGo et. al. 1.999) y, en nuestra zona -vertiente sur- las lagunas de El Padul (Granada) y Fuente de Piedra (Málaga), entre otras (Referencia de J. Arias García, tesis doctoral en prensa). La existencia de episodios de lluvias intensas a lo largo de un número de días y horas limitado, aunque exista una cubierta vegetal importante, la saturación del suelo provoca caudales no soportables incluso por algunos de los mayores cauces, condicionados además por la ocupación de los lechos de inundación.

El Cuerpo de Montes, desde su creación en el año 1.853, se ha venido ocupando del problema de las inundaciones y sus efectos como se aprecia en los numerosos artículos publicados en la revista Montes. La idea directriz es que el problema de las inundaciones se podría remediar con la reforestación y la corrección hidrológica. Las actuaciones tendentes a evitar tales desastres y remediar en lo posible los daños estuvieron siempre presentes en los poderes públicos y dichas actuaciones tendrían a su vez una gran influencia sobre el resto de elementos causantes del problema. La repoblación forestal y sobre todo la restauración de cuencas hidrológicas, la denominada en el mundo forestal restauración hidrológico-forestal, tendría repercusión sobre la red hídrica, regulando y conservando los cauces. En este sentido, en la generación y/o agravamiento del problema tuvieron una gran incidencia las agresiones contra los montes públicos, muy importantes a lo largo del tiempo, factor determinante en la desnudez del suelo de la que tanto eco se hicieron los sectores sociales y que tanto empeño puso en resolver la administración forestal con el cuerpo de montes al frente. Este se centró en principio en la defensa de la Propiedad Forestal Pública, que derivaría en el nacimiento del Catálogo de Montes que actualmente cuenta con un importante elenco de montes con una gran diversidad de ecosistemas de titularidad pública. Sin embargo, ello resultó luego insuficiente para resolver el problema grave de deforestación que padecía buena parte del país y concretamente nuestro ámbito de estudio. No resultaba suficiente como se ha dicho con la propiedad pública, para la que ya existían actuaciones repobladoras. Era necesario incorporar al elenco de los montes de titularidad pública otros de carácter privado que, debían aportar lo necesario para la mejor solución del problema. Un cambio esencial en el concepto con el que se había venido trabajando por la Administración. Por esta razón y para este fin se pone en marcha una nueva política destinada a la declaración de zonas protectoras.

Una de las razones que justificaban la necesidad de la repoblación forestal o en su caso la completa restauración hidrológico-forestal fue el problema de la deforestación que padecían muchas zonas de las provincias de referencia. En este sentido, habría de sumar las lluvias torrenciales a causa de la climatología 
adversa constatada históricamente. La denominada «gota fría» (hoy DANA) que se reproducía, principalmente en algunas zonas de nuestra zona de estudio como la cuenca del Guadalmedina en la ciudad de Málaga y el sureste de la provincia de Granada. ${ }^{7}$ Ello ocasionaba inundaciones ${ }^{8}$ de gran importancia que tenían como resultado, además de las importantes pérdidas de cultivos e incluso vidas humanas, la pérdida de suelo agrícola y una gran erosión del suelo, con el que se cerraba el círculo y se iba agravando progresivamente el problema al que había que buscar una solución. Pero al igual que la creación del problema que duró siglos, la solución tampoco podía ser inmediata, no existía una fórmula para ello por lo que se acudió a muchas iniciativas, todas ellas con el mismo propósito, devolver a la naturaleza su estado ecológico, óptimo para el bien social, muy reclamado además en distintos ámbitos de la sociedad, culturales, científicos, políticos y técnicos.

\section{EL PROBLEMA FORESTAL Y LAS INUNDACIONES HISTÓRICAS SURMEDITERRÁNEAS}

Queda constatada la gran relación, evidenciada hace tiempo, entre las inundaciones y el problema de la deforestación. Así se había venido reclamando a lo largo del tiempo por numerosos autores y repetido el discurso del Cuerpo de Montes en el sentido de que la solución al problema radicaba en la reproducción de una importante cubierta vegetal arbórea que retuviera las temidas lluvias torrenciales.

En la vertiente surmediterránea de Granada, situada al sur de Sierra Nevada (Mulhacén, 3.489 m), entre ésta y sus paralelas prelitorales (Contraviesa. Lújar..) nos encontramos una serie de ríos, arroyos y ramblas, destacando la cuenca del río Guadalfeo que presenta unas características físicas y humanas modélicas de la vertiente mediterránea andaluza, tanto por su variada y contrapuesta naturaleza (topografía, climatología, hidrología, vegetación, suelos etc.) como por su utilización antrópica secular y actual. Al sur de las sierras prelitorales en contacto directo con el mar encontramos una intensificación parcial de este modelo, que en términos hidrológicos se concreta en una mayor aridez y en numerosas ramblas que vierten directamente al Mediterráneo tanto sus caudales semipermanentes como los esporádicos e intensivos asociados con episodios torrenciales de diversas características. Frente a los $1.295 \mathrm{~km}^{2}$ de la cuenca de Guadalfeo estas pequeñas subcuencas litorales apenas abarcan $170 \mathrm{Km}^{2}$.

7. Capel Molina, J.: «Génesis de las inundaciones de octubre de 1.973 en el sureste de la Península Ibérica». Cuadernos Geográficos (Granada) n. 4, 1974, pág. 149-166. Departamento de Geografía. Facultad de Filosofía y Letras. Granada. 1974.

8. CATÁLOGO NACIONAL DE InUNDACIONES HistóRICAS. Aplicación informática desarrollada por la Dirección General de Protección Civil y Emergencias (DGPCE), Ministerio del Interior. Red de Información Ambiental. (REDIAM). Consejería de Medio Ambiente y Ordenación del Territorio. Junta de Andalucía. 
Figura 2: Cuenca del Río Guadalfeo en la provincia de Granada

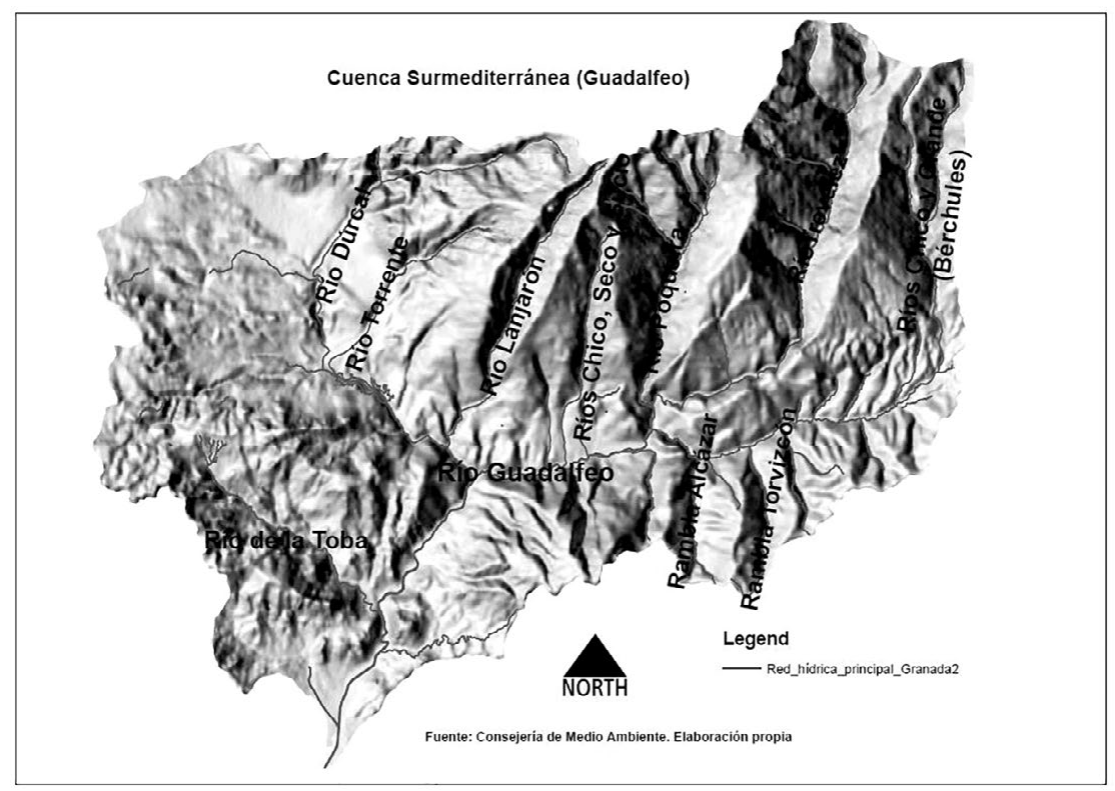

Fuente: Mapa de sombras y red hidrológica (REDIAM). Consejería de Medio Ambiente y Ordenación del territorio. Junta de Andalucía. Elaboración propia.

Tanto en estas cuencas costeras orientales granadinas como en las más occidentales, ubicadas tanto en Granada (Verde, Seco) como en Málaga, las inundaciones son un hecho habitual, aunque su frecuencia e intensidad guarda relación tanto con la progresiva degradación de la pluviometría hacia el Este y la magnitud de las respectivas cuencas. En la cuenca granadina del Guadalfeo (figura 2) las inundaciones son una constante histórica y de especial intensidad desde la segunda mitad del siglo XIX (gráficos 1.1 y 1.2). La restauración forestal se inicio pronto, hacia 1860 , como después veremos, tras las inundaciones en Lanjaron y Órgiva. Por otra parte, en el siglo xx, avanzada ya la corrección, continúan las avenidas, tanto en el río principal como en las cuencas afluentes y costeras, destacando entre estas últimas las de la Rambla de Albuñol-La Rábita... Por otra parte, la forografía n. $^{\circ} 1$ muestra el efecto de las avenidas en la creación del delta y, sobre todo, la creciente ocupación de este por cultivos e infraestructuras.

No obstante, si bien las inundaciones afectaron a la mayoría de las sucuencas de la vertiente surmediterránea, en la provincia de Málaga, fueron sin duda las de los Ríos Guadalmedina y Guadalhorce las que se vieron más afectadas por el problema de las inundaciones históricamente (grafico 2). Además de la 
Grafico 1.1. Inundaciones históricas producidas entre los años 835 y 1985 en los ríos de la provincia de Granada

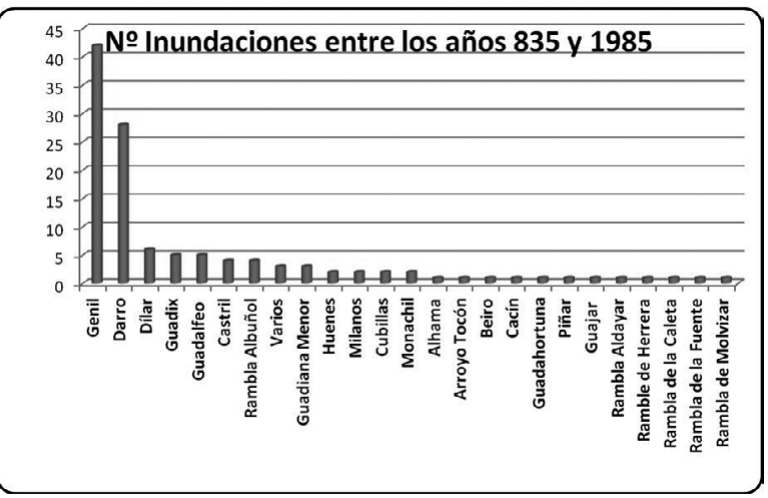

Fuente: Catálogo de Inundaciones Históricas. Aplicación informática desarrollada por la Dirección General de Protección Civil y Emergencias (DGPCE), Ministerio del Interior. Red de Información Ambiental. (REDIAM). Consejería de Medio Ambiente y Ordenación del Territorio. Junta de Andalucía. Elaboración propia.

Grafico 1.2. Inundaciones históricas en la cuenca del Guadalfeo y costeras granadinas

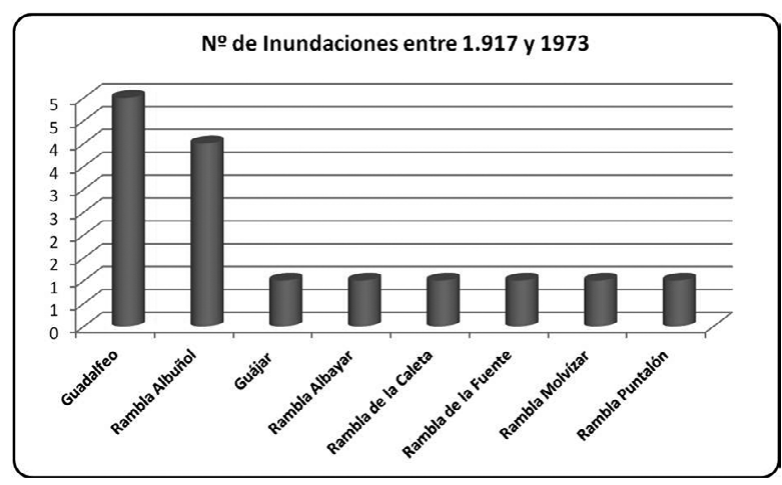

Fuente: Idem. Gráfica 1.1. mayor frecuencia de los episodios de inundaciones, éstas se producían en las zonas donde más perjuicios ocasionaban, en el caso del Río Guadalmedina porque su cauce discurre por el centro de la ciudad de Málaga y en el caso del Guadalhorce porque éste se encuentra próximo a la ciudad de Málaga y su vega y cono de deyección han mantenido una gran importancia para la agricultura y otros usos. Entre 1.544 y 1.979 se produjeron en la zona de influencia del río Guadalmedina 40 episodios de avenidas que se distribuyeron a lo largo de los años sin que destaque especialmente periodo alguno de mayor incidencia, la media de años en las que se venían produciendo fue de diez y la estación del año vendría a coincidir con el otoño principalmente.

La cuenca del Río Guadalmedina tiene un carácter marcadamente torrencial. La superficie total de la cuenca es de 18.226,33 hectáreas, de

las cuales corresponden a monte público (Monte Cuenca del Guadalmedina, MA10001JA) un total de 4.811,6 hectáreas, lo que equivale a algo más del $26 \%$. Ante el problema de las inundaciones que se producían en la ciudad de Málaga, la Administración Forestal promovió una serie de actuaciones principalmente 
Foto 1: El delta del Guadalfeo en 1956 y 2007

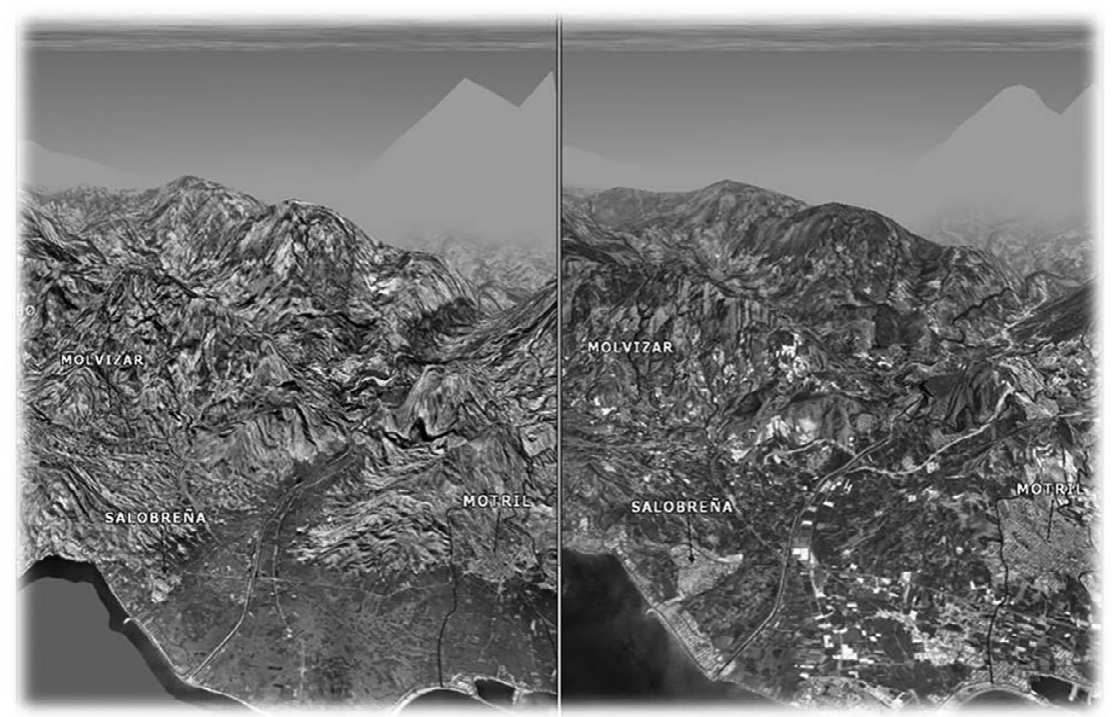

Fuente: Ortofotografía Digital Histórica de Andalucía 1956-2007, medio siglo de cambios. Elaboración propia.

destinadas a la corrección hidrológico-forestal en el monte que administraba. Las avenidas en el Río Guadalmedina fueron continuadas durante siglos afectando a la ciudad de Málaga. Sin embargo, la causa principal por la que se inician o se hacen mas frecuentes las avenidas a partir de determinada época, se encuentra en que a comienzos del siglo XVI se descuajan los montes situados en su cabecera para implantar el cultivo de la vid, por su alto rendimiento y por la calidad de los mostos que de ella salían que dieron fama universal a Málaga. Paralelamente a esta transformación cambia también el régimen del río, que se convierte en

Gráfico 2: Inundaciones históricas producidas en los cauces de la cuenca Surmediterránea Andaluza. Provincia de Málaga 1544-1979

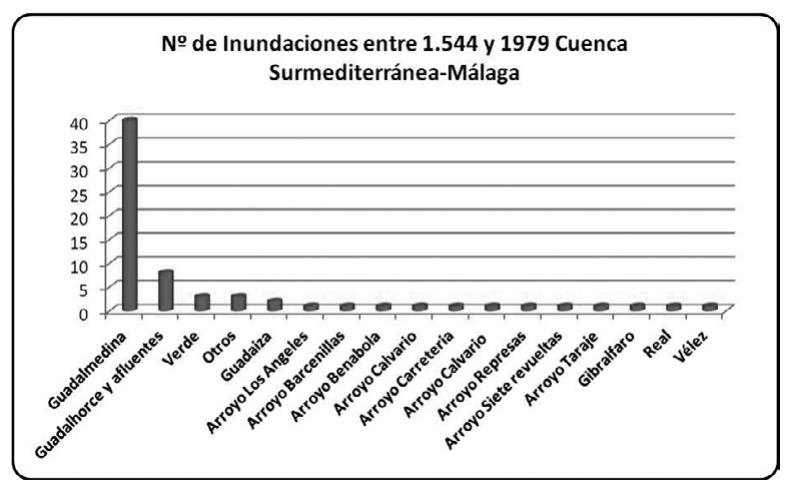

Fuente: Ídem. Gráfica 1.1. 
torrencial con grandes alternativas de crecidas y sequías (Martinez Falero y Arregui, 1950).

Un hecho revelador, aparentemente paradójico que queda recogido en las crónicas de la época, es el siguiente. Entre el 28 de octubre de 1434 y hasta marzo de 1835 se produjo un régimen de lluvias intensas en toda España que ocasionó inundaciones en todas partes excepto en Málaga, porque a pesar de producirse fuertes avenidas en el Guadalmedina, la ciudad de Málaga resistió a las mismas gracias a la entereza de los muros y a la profundidad del lecho del río y la caja que lo guardaba (Martinez Falero y Arregui, 1950, cita a Milla 1.802). De lo que se desprende que el problema de las inundaciones en este caso radicaba más en las dimensiones del cauce que en esta época era capaz de evacuar la cantidad de agua que el río acumuló en su cuenca por las lluvias constantes que se produjeron. Como habría ocurrido también durante la antigüedad y el medioevo con una cuenca arbolada y todavía no roturada masivamente. Esta situación cambiaría tras la Reconquista, en la que siguiendo las crónicas citadas, en el año 1.487; en el cabildo celebrado por el Iltre. Ayuntamiento en el año 1490 se prohibió que bebieran los ganados en el Guadalmedina para que no enturbiasen las aguas que usaban los vecinos, según el Acuerdo. En otros

Gráfico n. ${ }^{\circ}$ 3: Variación experimentada por el cauce del Guadalmedina a través de la población 1.400-2.000 Previsión

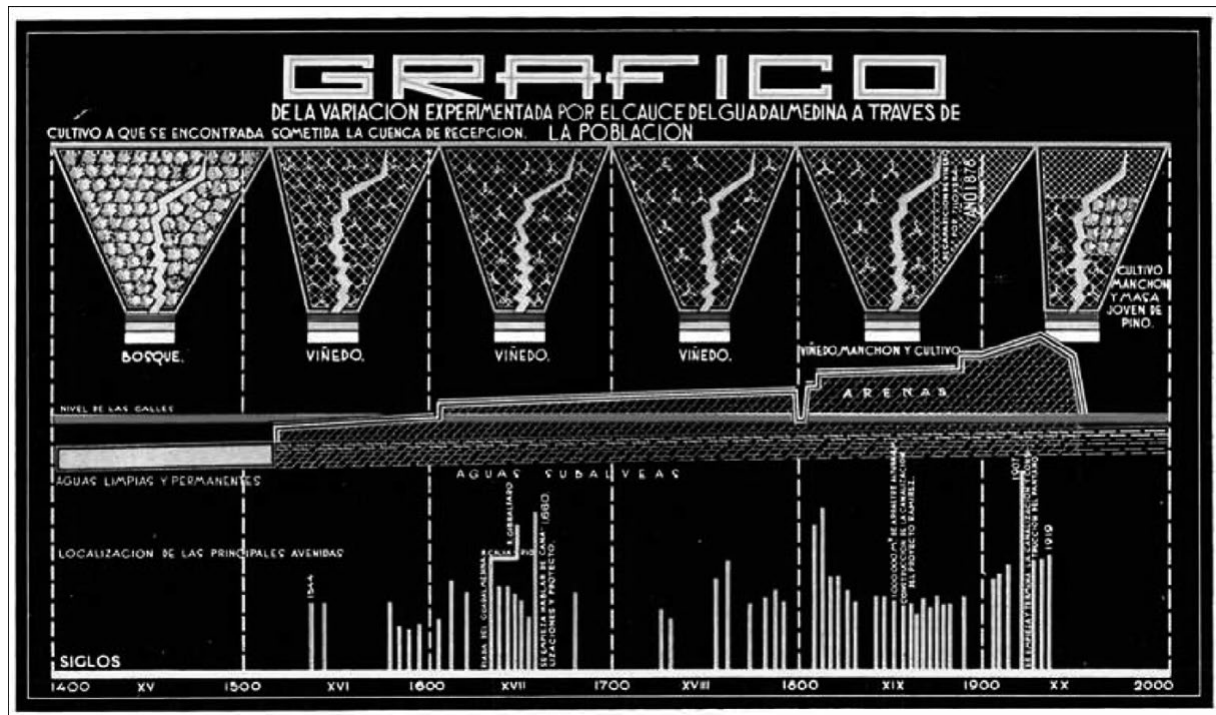

Fuente: Trabajos hidrológico-forestales realizados en la capital de Málaga para su defensa contra las inundaciones y daños producidos por los torrentes y ramblas. José Martínez Falero y Arregui. Revista Montes n. ${ }^{\circ} 33$. Año 1950. Páginas 293-335. 
Foto 2: Ortofotografía digital de la Cuenca del Río Guadalmedina sobre Modelo Digital del Terreno y Elevaciones, comparada entre los años 1956 y 2007

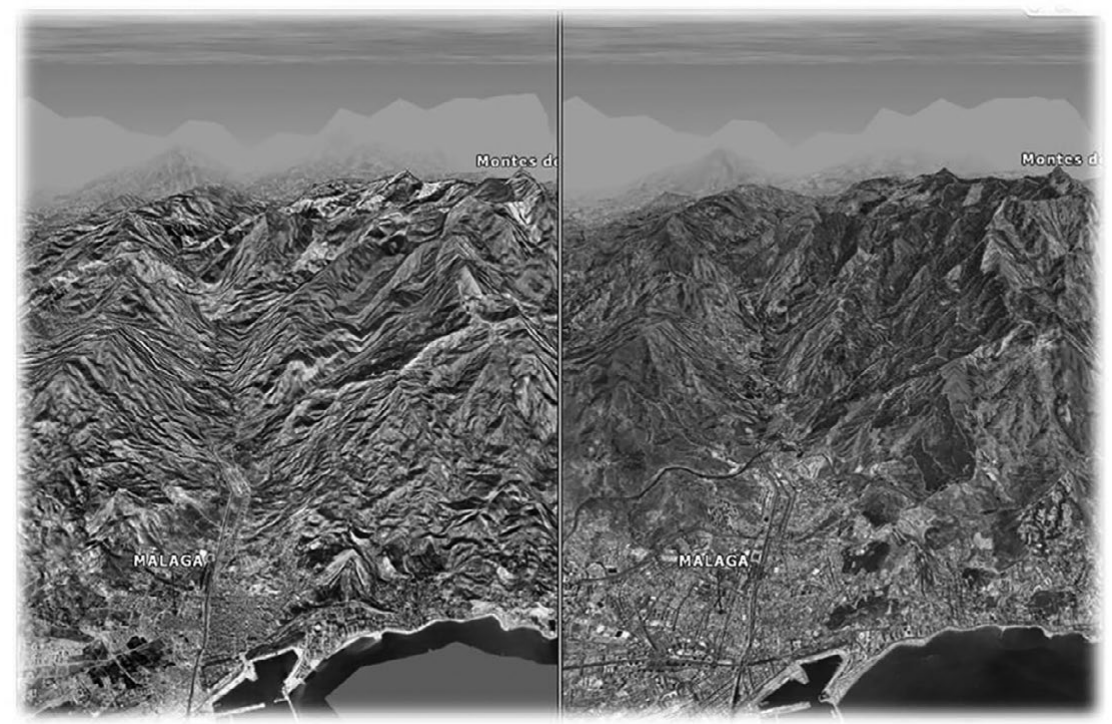

Fuente: Ortofotografía Digital Histórica de Andalucía 1956-2007. Medio siglo de cambios en Andalucía. Junta de Andalucía.

acuerdos posteriores se dictaron las mismas órdenes aunque dirigidas a ganado concreto como el de cerda e incluso se impusieron penas para los transgresores.

La idea de que la carencia de vegetación en la cabecera de las cuencas hidrográficas surmediterráneas, y en concreto la del Guadalmedina, fue la responsable de la aparición de las inundaciones catastróficas a partir del siglo XVI. El descuaje del arbolado va a producir la colmatación del cauce, de forma que este subía de nivel progresivamente conforme a la aportación de sedimentos arrastrados desde la cabecera por la erosión. El modelo evolutivo es el que refleja el gráfico $\mathrm{n}^{\circ}{ }^{\mathrm{o}}$ 3. Llegado el siglo xx la frecuencia las avenidas continuarían hasta los años cuarenta en que siguieron siendo un verdadero problema para Málaga. A partir de esa fecha la cabecera del Guadalmedina se ve modificada en los usos del suelo, desaparecen los viñedos para dar paso a otros cultivos menos intensivos, matorral y aparecerá la repoblación forestal. La nueva estructura de los usos del suelo con la perdida del viñedo a favor de la repoblación cubririan la superficie erosionable. A ello se añadiría la menor frecuencia de las lluvias torrenciales y las nuevas técnicas de ingeniería civil que regularon los cauces determinando la práctica desaparición del problema en la actualidad. 
La imagen comparada del cauce del Guadalmedina sobre el Modelo Digital del Terreno y Elevaciones (MDTE, Foto . $^{\circ}$ 2) nos da una idea de la situación del mismo, desde el nacimiento del río en Villanueva del Trabuco en el Pico de la Cruz de la Sierra de Camarolos a 1.433 metros de altitud y una distancia desde el nacimiento a la desembocadura nivel del mar en la ciudad de Málaga de algo más de cincuenta y un kilómetros. Como vemos, el cauce desciende en línea recta y a partir de los primeros kilómetros se produce un descenso prolongado del río y forma una llanura que sería el cono de deyección inicial en el que se encuentra situada la ciudad de Málaga, en estas condiciones las avenidas causaban importantes daños a la población y a los bienes. Como ejemplo, siguiendo a Martínez-Falero, en el siglo XVII los daños fueron los siguientes:

Cuadro 1: Pérdidas sufridas en la cuenca del Guadalmedina S. XVII

\begin{tabular}{|l|c|}
\hline \multicolumn{1}{|c|}{ Daños } & Importe Reales \\
\hline 418 casas derrumbadas & 836.000 \\
\hline 400 casas averiadas & 160.000 \\
\hline 1500 casas inundadas & 150.000 \\
\hline 10.000 arrobas de aceite de las bodegas & 27.000 \\
\hline Enseres de las casas destruidos, dinero, joyas de oro, etc.. & 836.000 \\
\hline Vino perdido & 50.000 \\
\hline 20.000 arrobas de pasa y almendras perdidas & 30.000 \\
\hline 48.000 fanegas de trigo y harina perdidas & 36.000 \\
\hline Pérdida de ganados & 20.000 \\
\hline Perdidas varias en edificios, cebada perdida, daños en los terrenos... & $\mathbf{8 3 3 . 5 0 0}$ \\
\hline Total........................................................ & $\mathbf{2 . 9 7 8 . 5 0 0}$ \\
\hline
\end{tabular}

Fuente: Martínez-Falero, Montes N. ${ }^{\circ} 199$ Volumen: IX Año 1885.

\section{LA TORRENCIALIDAD Y LA DESERTIFICACIÓN}

El suelo, formado durante millones de años mediante continuos ciclos naturales, unos in situ, otros transportados, de origen aluvial o coluvial, es el complejo viviente más afectado y transcendente en el problema de la erosión. Conocido por los poderes públicos se dictaron normas de defensa contra la erosión. Los montes constituyen en este sentido un territorio de primera magnitud. Como decía, ya en 1868, el ingeniero García Martino, seguidor de Von Liebig, "el origen de la ruina de las naciones no es accidental, están, por el contrario, sujetos a una misma ley de la naturaleza. La esterilidad de la tierra, la pérdida de los elementos que constituyen su fertilidad, ocasiona su empobrecimiento o 
su desaparición; la conservación de dichos elementos las hace permanentes, ricas y poderosas») $)^{9}$.

La torrencialidad y la erosión del suelo van unidas en el tiempo y el espacio. Sin embargo, desde el punto de vista jurídico no existe una normativa de protección del suelo per se, aunque existe un Derecho Ambiental en el que se incluiría. La protección de los suelos frente a la erosión ha sido muy estudiada en geografía sobre todo en relación con los riesgos naturales. Shepherd ${ }^{10}$ sentenció en 1.947 que hay «dos formas en que los humanos son capaces de aniquilar una civilización, una es la guerra total y la otra la erosión del suelo; de ambas, «la erosión del suelo es la más insidiosa y la más destructiva». Según Martin Mateo «se puede afirmar con una cierta rotundidad que la erosión del suelo es, en estos momentos, el problema ambiental número uno de nuestro país.» ${ }^{11}$. La misma postura mantiene el plan Nacional de Restauración Hidrológico- Forestal.

El problema torrencial y el de la erosión del suelo no se produjeron en un momento concreto provocando las inundaciones en determinadas áreas de nuestro entorno. Esta situación venía siendo un problema secular que se producía de forma permanente. El fenómeno de la torrencialidad, la unión de la acción de la naturaleza y del hombre hace posible la escorrentía y erosión del suelo, la intensidad de las lluvias, propia de las tormentas de verano sobre una tierra árida hacen posible que pueda ser peor que si no lloviera (Sánchez Ramos, 2.010) ${ }^{12}$. A pesar de que se podría considerar en muchos casos que es una actividad natural que se produce por los efectos de la morfogénesis, la erosión comienza a suponer un problema a partir del momento en que la tasa de erosión supere la edafogénesis. En tanto los terrenos están sometidos a un rejuvenecimiento del perfil edáfico que les impide progresar hacia niveles más maduros y productivos (Rojo Serrano, 1.939.)

Son varios los autores que han definido con claridad al torrente, por ejemplo García Nájera (1962) sigue la teoría de Scipión Gras ${ }^{13}$ que lo establece a partir de la saturación del suelo, « es una corriente natural de agua cuyas crecidas son súbitas y violentas; sus pendientes fuertes e irregulares, y que, por regla general, deposita en ciertas partes de su lecho los materiales acarreados

9. Arriola Calleja, T. 1.955. La erosión del suelo español a través de la Legislación Forestal. Revista Montes N. ${ }^{\circ} 61$ Año 1955 páginas 19-26.

10. Citado por Crespo Llanes, A. El Control Jurídico de la erosión del suelo. La Desertificación. Tesis doctoral. Universidad de Alicante. 2.000.

11. Martin-Mateo, R.: Tratado de Derecho Ambiental -, vol. 1, Ed. Trivium, 2.001, pág. 209.

12. SÁNChez Ramos, Valeriano:»El Andarax, una singularidad del sureste». En Andarax. Agencia Andaluza del Agua. Junta de Andalucía. 2010, pág., 13.

13. García NáJera, J.M.: Principios de Hidráulica Torrencial, su aplicación en la corrección de torrentes. Ministerio de Agricultura. Instituto Forestal de Investigaciones y Experiencias. Madrid 1962. 
Figura n. ${ }^{\circ} 3$ Desertificación heredada. Provincias de Granada y Málaga

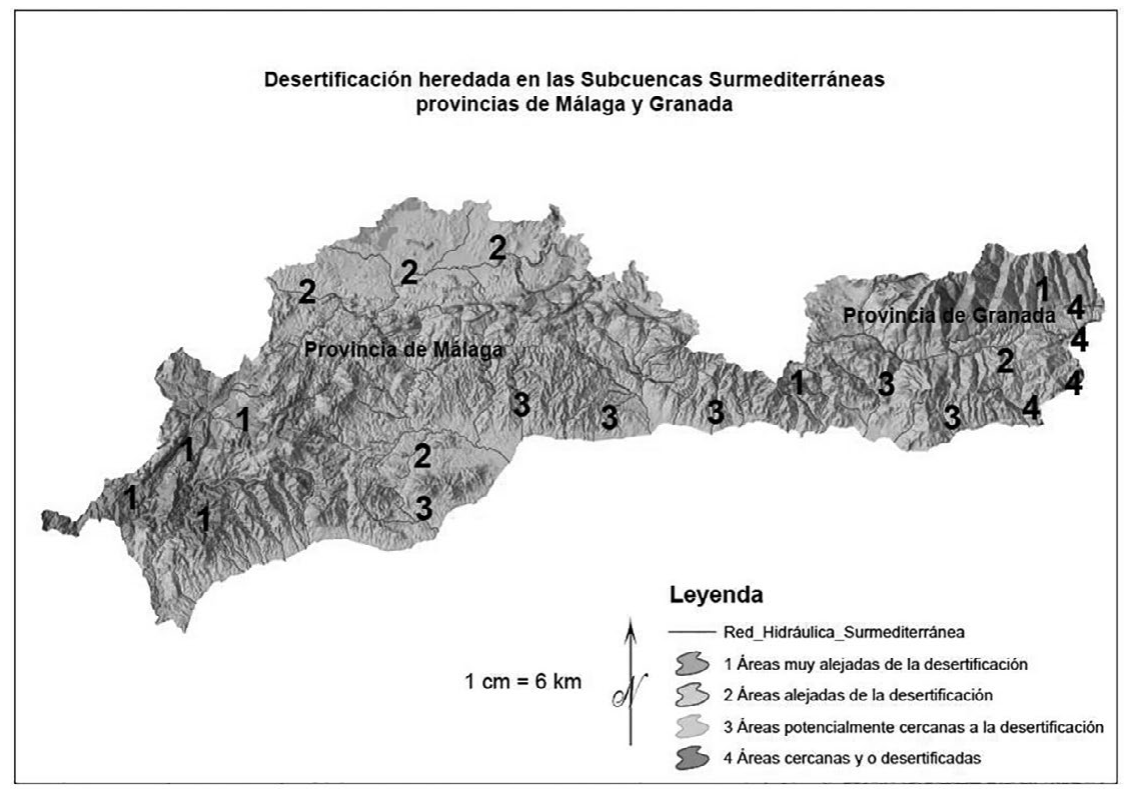

Fuente: Red de Información Ambiental. (REDIAM). Consejería de Medio Ambiente y Ordenación del Territorio. Junta de Andalucía. Elaboración propia.

por las aguas» $[\ldots]$ son dos los caracteres que se le atribuyen a los torrentes en esta definición: la intensidad y la repentina aparición de las crecidas, y la magnitud e irregularidad de las pendientes»[...]. En este mismo sentido, plantea que la formación de un torrente «viene a ser una síntesis del trabajo de las aguas corrientes».

Con estas definiciones y por las características de los cauces surmediterráneos de las provincias de referencia, especialmente la de Granada, podemos considerar que una parte importante de la red hídrica tiene o ha tenido problemas de torrencialidad. Problemas como consecuencia de las constantes pérdidas de suelo que causaron algunos cauces han derivado en la desertificación de buena parte de la vertiente surmediterránea (gráfico n. ${ }^{\circ}$ 5). Por ello, las iniciativas correctoras de las Cuencas hidrográficas son tempranas en esta provincia, sobre todo en la vertiente sur de Sierra Nevada. ${ }^{14}$

14. [...] «múltiples vicisitudes de su larga historia han dado lugar a una deforestación profunda, las condiciones peculiares de su clima debían dar como resultado el que el fenómeno torrencial adquiriese proporciones considerables». [...] Y en efecto: la región pirenaica, con sus torrentes de tipo alpino, al igual que muchas de Sierra Nevada y toda la zona levantina, [...] nos muestran en abundancia esas corrientes de agua de pendientes fuertes e irregulares y 
Por Real Decreto de 3 de febrero de 1.888 se organizan los primeros trabajos de repoblación de las cabeceras de las cuencas hidrológicas de España. Una Real Orden de 28 de julio dispone que para el cumplimiento del citado Real Decreto, se preste atención preferente, entre otras, la cuenca del Guadalquivir que, tras la reorganización del servicio por Real Decreto de 7 de Julio de 1.901 incluye, entre otras zonas surmediterráneas, el macizo de Sierra Nevada, «un gran promontorio(sic) donde
Foto 3: Sierra Nevada. Cono de deyección del torrente de las Adelfas. Fototeca INIA Cuenca del Guadalfeo. Otoño de 1934

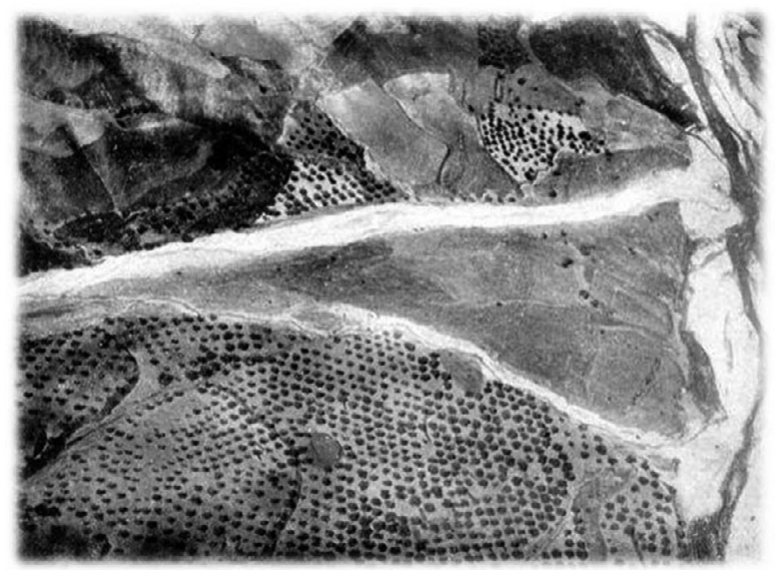

Fuente: Foto aviación. Reproducido de Casado, Lorenzo J. El Servicio Forestal de la Confederación Hidrográfica del Guadalquivir. Sevilla. 1.934. Fototeca Forestal Española DGB-INIA.

se encuentran las mayores altitudes con algunas peculiaridades añadidas como son, la gran extensión superficial, las dos vertientes, tanto la Mediterránea como la Atlántica con ríos muy cortos que descienden de una gran altitud en un espacio muy reducido y de ahí su carácter torrencial, principalmente los de la vertiente mediterránea. La divisoria principal es el promontorio (sic) de Sierra Nevada donde se encuentran los picos más elevados de la provincia (sic) (Mulhacén 5.481 m., Veleta 3.470 m. La Alcazaba, 3.314 m., El Chullo, 2.611 m.» Figura 3 y foto n. ${ }^{\circ} 3$ )

Esta situación estaba vinculada a varios factores a tener en cuenta, sobre todo la falta de cubierta vegetal y la importante torrencialidad en las cabeceras de las cuencas hidrográficas. Debido a las numerosas inundaciones, existía una gran conciencia en la administración forestal y muy especialmente entre los responsables del cuerpo de Montes a todos los niveles. La grave situación de la vegetación pesaba sobre los miembros de la administración forestal, que se pronunciaban al respecto reclamando mayores recursos para afrontar la situación.

súbitas crecidas, donde se manifiestan los fenómenos de erosión, transporte y depósito de materiales con gran intensidad, causa de gravísimos perjuicios» [...] García Nájera, J.M. 1.962. 
Un ejemplo de ello lo encontramos en 1.918 en el Ingeniero D. Pedro A. Mesa en su «Memoria de reconocimiento del Guadalquivir» ${ }^{15}$.

Las actuaciones se centraron en aquellos lugares que tradicionalmente venían ocasionando el mayor problema foresta ${ }^{16}$. La repoblación fue una de las intervenciones, ya que en la mayoría de los casos ésta estaba acompañada de otras actuaciones que, en su conjunto, constituyen lo que en el entorno profesional vino a denominarse oficialmente restauración hidrológico-forestal. En este concepto se creyó encontrar el paradigma de solución de los problemas seculares de torrencialidad y así se hizo. En el caso de la Cuenca del Guadalfeo, la más torrencial de España como han mencionado algunos autores ya citados, veníanse realizando, al menos desde 1860, trabajos de los denominados hidrológico-forestales, que incluían, además de la regeneración del arbolado, la construcción de diques de distintas características y dimensiones. La zona estaba dividida para los trabajos en secciones. El entonces responsable del área, el Ingeniero de Montes Antonio Romero Zurbano, ya venía ocupándose de este problema en la zona, como consecuencia de la catástrofe ocurrida en el año 1860 que produjo, entre otras cosas, un impresionante socavón que desde entonces se denominó el «Rehundido» por lo que se iniciaron trabajos en tres grandes cauces que anteriormente se tenían por inofensivos (los arroyos conocidos como Río Seco, Río Chico y Río Sucio), situados en dirección norte-sur.

En opinión del Ingeniero A. De Castro, la eficacia de las actuaciones realizadas en la Cuenca del Guadalfeo quedó demostrada. Lo pudo comprobar en una visita de inspección ${ }^{17}$ que realizaba a la sección del Guadalfeo.

15. ANÓNIMO: Revista Montes n. ${ }^{\circ}$ 102, año 1918. El problema forestal en la División Hidrológicoforestal del Guadalquivir. Año 1918.

16. La zona estaba dividida en tres perímetros, el primero se centraba en el «Rehundido» en la cuenca del Río Chico (Perímetro I), el segundo perímetro donde se efectuaban los trabajos fue el que estaba situado en la zona del Rio Seco (Perímetro II) y el Rio Sucio en el III perímetro.

17. «Regresábamos de la casa forestal de Soportújar para tomar el coche en Órgiva, y nada anormal nos llamó la atención durante las pocas horas que allí permanecimos, hasta las dos de la tarde en que tomamos la diligencia que habia de conducirnos a Granada; atravesamos el lecho del río Chico, que pasa muy cerca de Órgiva, sin que apenas trajera agua, ni mucho menos arrastre de ninguna clase, y a la media hora escasa estábamos a orilla del otro barranco, llamado el Sucio, viéndonos desagradablemente sorprendidos al notar que traía una importante avenida de agua y fango de más de un metro de alto, que nos imposibilitaba de todo punto de seguir el viaje; entonces nos enteramos de que aquella mañana había llovido con relativa abundancia en la parte alta de la cuenca, y que las aguas procedentes de estas lluvias, que no habian tenido, al parecer, extraordinaria intensidad, eran las causantes de aquella inesperada avenida. Cuatro horas largas se invirtieron en hacer pasar la diligencia en brazos de hombres, con el agua a la cintura, y gran trabajo de las caballerías, teniendo los viajeros que remontar el arroyo para buscar, aguas arriba, un paso posible aunque fuera peligroso, y llegamos a Granada con un considerable retraso, pero teniendo ocasión de observar la fuerza extraordinaria que alcanzan estos verdaderos torrentes que descienden de lo alto de la Sierra Nevada, con solo que se produzcan lluvias de alguna intensidad en la parte alta de 
Los trabajos dirigidos desde 1.906 por el Ingeniero aludido estuvieron Los concentrados en el perímetro del Rehundido) y consistieron en la construcción hasta ese momento de un total de seiscientos veintidós diques, a los que se acompañó como complemento una práctica muy regular, las estacadas de sauce. ${ }^{18}$ Se consiguió con estos trabajos la consolidación de las movedizas laderas existentes en el área. Pero siguiendo el ejemplo, los vecinos de Carataunas que se veían amenazadas por los deslizamientos y arrastres ya iniciados en las laderas próximas al pueblo, solicitaron la realización de nuevos trabajos de corrección. El Ingeniero Romero, proyectó en esa zona la construcción de nuevos y más consistente diques. Se iniciaron los trabajos de los dos primeros, pero en plena construcción del segundo dique se produjo un gran temporal que duró desde los días 4 al 13 de diciembre en Sierra Nevada.

Desde entonces los trabajos, con algunas interrupciones notables.han continuado en la misma línea inicial pero complementada por un mayor rigor en la recuperación de la cubierta vegetal en relación con las series de vegetación de la zona y otros aspectos (Almagro, J. Torrentes y Pantanos en Sierra Nevada, 1932) relacionados con el suelo y la hidrografía. En este sentido se pronuncian otros autores que inciden la gran heterogeneidad de los comportamientos, directamente dependientes de las variables climatología, topografía, litología, cubierta vegetal y usos del suelo. La Cuenca del Guadalfeo, con la red hídrica más densa de la Península, presenta coeficientes de escorrentía, caudales específicos e hidrogramas que oscilan entre los propios del régimen nival húmedo y los de régimen pluvial semiseco. (Castillo, 1.999; Rodriguez Martínez, $2004)^{19}$

Las actuaciones en materia de restauración hidrológico-forestal se ha visto condicionadas por el nuevo contexto científico, técnico y económico, especialmente a partir de los años sesenta del siglo xx. También el nuevo contexto instucional que supuso primero la creación del ICONA y la nueva legislación ambiental del Estado y las Comunidades autónomas. La producción científica

la cuenca». Aquí, se detecta el régimen pluvionival de Sierra Nevada, principalmente en la vertiente sur. Reseña del temporal de aguas que se desarrolló en Sierra Nevada, entre los días 4 y 13 de diciembre de 1910, poniendo a prueba los trabajos hidrológico-forestales ejecutados en la cuenca del Guadalfeo. Efectos del temporal de la primera quincena de diciembre de 1.910 en la cuenca del Guadalfeo (Granada)r: Fernández DE CASTRO, A. Revista Montes N. ${ }^{\circ}$ 817 Vol. XXXV Año 1911 páginas 91-96.

18. Las estacadas de sauce consistían en la preparación de una barrera de estacas de sauce verde situadas en el entorno del dique, las cuales una vez consolidadas formaban la recuperación de la vegetación de ribera evitando así el descalzado del dique y su posible arrastre y desaparición.

19. Castillo Martín, A.: «Agua y acequias en la Alpujarra». En II conferencia de la Alpujarra, 19, págs. 151-164. Rodríguez MarTínez, F. »Los derrames penibéticos». En Gil Olcina, A. (coord...): Alteración de los regímenes fluviales peninsulares, Fundación Caja Murcia,2004,págs.. 439-495. 
Figura n. ${ }^{\circ}$ 4. Estados erosivos de la Cuenca del Guadalfeo, perteneciente a la Cuenca Mediterránea. Reproducción parcial a partir del Mapa de Estados Erosivos de la Cuenca Hidrográfica del Sur de España

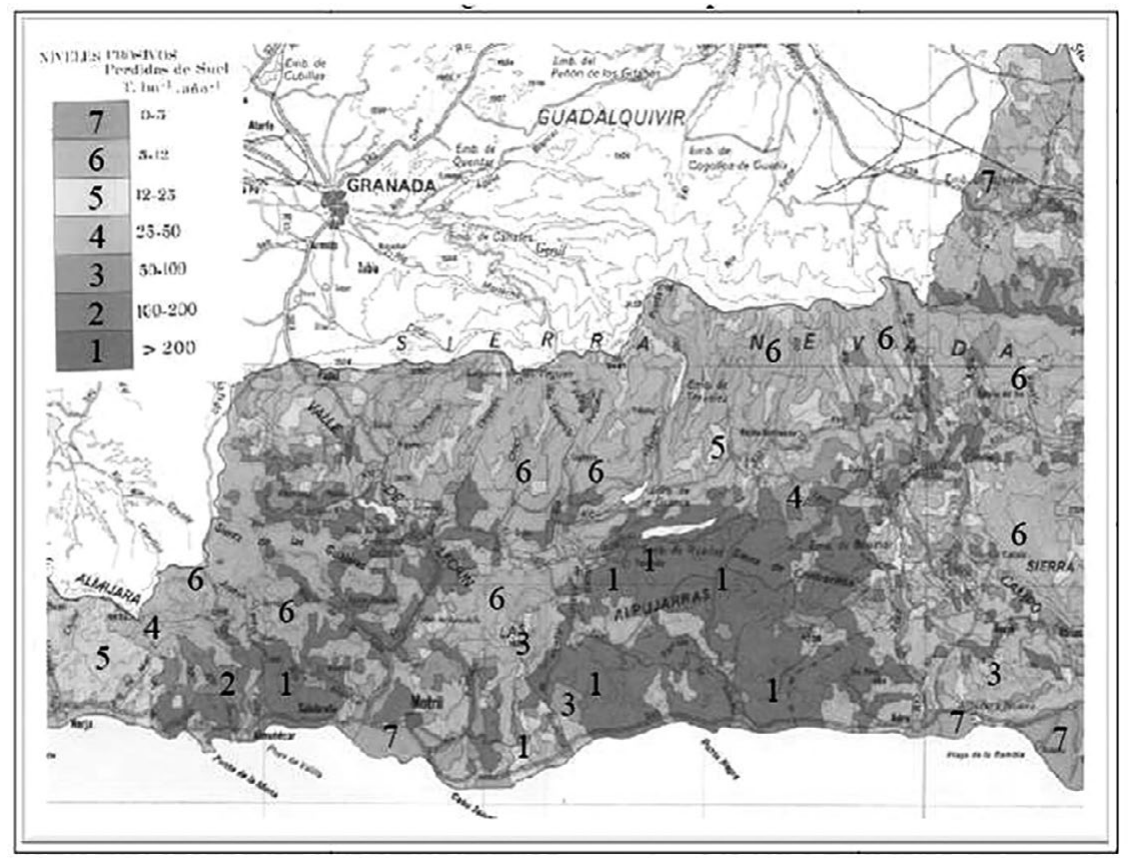

Fuente: ICONA 1990. Los estudios señalan el máximo nivel de erosión en la vertiente sur de Sierra Nevada y la Sierra de la Contraviesa, tanto en su vertiente norte hacia el Guadalfeo, como en la vertiente sur hacia el Mediterráneo, como vemos en el mapa en estas zonas los niveles erosivos están por encima de las 200 toneladas y hectárea al año.

sobre el problema erosivo en el área mediterránea es desde entonces muy abundante desde variados puntos de vista.

Por destacar algunos de los trabajos que afectan a nuestra área de estudio, en 1990, el Instituto Nacional para la Conservación de la Naturaleza (ICONA) desarrolla el Mapa de Estados Erosivos de la Cuenca Hidrográfica del Sur de España (Figura 4).

Otro de los trabajos que resulta de más interés para el tema de este trabajo y para nuestro ámbito es el que se enmarca dentro del proyecto LUCDEME, un estudio denominado «Evaluación sistemática de las acciones de repoblación forestal para la lucha contra la desertificación aplicadas en las cuencas del Adra y el Guadalfeo (Granada y Almería)». En el cuadro n. ${ }^{\circ} 2$ se recogen los proyectos de restauración hidrológico-forestal llevados a cabo desde 1931. Puede apreciarse la continuidad de las actuaciones y también el cambio de 
cuencas y el perfil de los trabajos a partir de 1965. Las actuaciones en materia de restauración hidrológico-forestal se ha visto condicionadas por el nuevo contexto científico, técnico y económico, especialmente a partir de los años sesenta del siglo xx. También el nuevo contexto instucional que supuso primero la creación del ICONA y la nueva legislación ambiental del Estado y las Comunidades autónomas. La producción científica sobre el problema erosivo en el área mediterránea es desde entonces muy abundante desde variados puntos de vista.

Cuadro 2: Relación de Proyectos de Restauración Hidrológico-Forestal desarrollados en la Cuenca del Río Guadalfeo y Vertientes directas al mar.

(1931-1979)

\begin{tabular}{|l|l|l|}
\hline Año & \multicolumn{1}{|c|}{ Título } & \multicolumn{1}{|c|}{ Cuenca } \\
\hline 1931 & $\begin{array}{l}\text { Proyecto de Corrección y Repoblación de la Cuenca del Rio } \\
\text { Torrente }\end{array}$ & $\begin{array}{l}\text { Cabecera del } \\
\text { Guadalfeo }\end{array}$ \\
\hline 1936 & $\begin{array}{l}\text { Proyecto de Corrección y Repoblación Forestal de la sección III } \\
\text { (Río Mecina) de la Cuenca del Rio Adra }\end{array}$ & Adra \\
\hline 1941 & Proyecto de Corrección y Repoblación de la Cuenca del Rio Pleito & $\begin{array}{l}\text { Cabecera del } \\
\text { Guadalfeo }\end{array}$ \\
\hline 1941 & Reforma del Proyecto de Corrección del Rio Torrente & $\begin{array}{l}\text { Cabecera del } \\
\text { Guadalfeo }\end{array}$ \\
\hline 1941 & $\begin{array}{l}\text { Proyecto de Corrección del torrente del Río Seco } \\
\text { Cabecera del } \\
\text { Guadalfeo }\end{array}$ \\
\hline 1942 & $\begin{array}{l}\text { Proyecto de Corrección y Repoblación Forestal de la Cuenca alta } \\
\text { del Rio Dúrcal }\end{array}$ & $\begin{array}{l}\text { Cabecera del } \\
\text { Guadalfeo } \\
\text { del Rio Poqueira }\end{array}$ \\
\hline 1943 & $\begin{array}{l}\text { Proyecto de Corrección y Repoblación Forestal de la Cuenca de la } \\
\text { Rambla de Molvízar }\end{array}$ & $\begin{array}{l}\text { Cabecera del } \\
\text { Guadalfeo }\end{array}$ \\
\hline 1944 & $\begin{array}{l}\text { Proyecto de Corrección y Repoblación Forestal de la Cuenca del } \\
\text { Río Sucio }\end{array}$ & $\begin{array}{l}\text { Cabecera del } \\
\text { Guadalfeo }\end{array}$ \\
\hline 1945 & $\begin{array}{l}\text { Proyecto de Corrección y Repoblación Forestal de la Cuenca } \\
\text { Secundaria del Río Tablate }\end{array}$ & $\begin{array}{l}\text { Cabecera del } \\
\text { Guadalfeo }\end{array}$ \\
\hline 1946 & $\begin{array}{l}\text { Proyecto de Corrección y Repoblación Forestal de las Cuencas } \\
\text { Secundarias de las Ramblas de la posta, Monjas, Palma, Junquillo, } \\
\text { Minasierra, Granja, Granadero, Los Bater, Pataura, Panaya y los } \\
\text { Álamos o Piojo } \\
\text { el Río Trevélez y su desembocadura en el mar y de sus afluentes } \\
\text { Río Chico, y Río Seco }\end{array}$ & $\begin{array}{l}\text { Vertientes al } \\
\text { mar }\end{array}$ \\
\hline 1947 & $\begin{array}{l}\text { Proyecto de Corrección y Repoblación Forestal de las riberas del } \\
\text { Rel Guadalfeo }\end{array}$ & $\begin{array}{l}\text { Guenca baja } \\
\text { Guadta }\end{array}$ \\
\hline
\end{tabular}




\begin{tabular}{|l|l|l|}
\hline Año & \multicolumn{1}{|c|}{ Título } & \multicolumn{1}{|c|}{ Cuenca } \\
\hline 1947 & $\begin{array}{l}\text { Proyecto de Corrección y Repoblación Forestal de las Cuencas de } \\
\text { las Ramblas del Chozón, Rejón y Trapiche }\end{array}$ & $\begin{array}{l}\text { Vertientes al } \\
\text { mar }\end{array}$ \\
\hline 1949 & $\begin{array}{l}\text { Proyecto de Corrección y Repoblación Forestal de la Cuenca del } \\
\text { Río Trevélez }\end{array}$ & $\begin{array}{l}\text { Cabecera del } \\
\text { Guadalfeo }\end{array}$ \\
\hline 1952 & $\begin{array}{l}\text { Proyecto de Corrección y Repoblación de las Cuencas del barranco } \\
\text { de Albayar, Rambla de Lobras y Río de Nieles }\end{array}$ & $\begin{array}{l}\text { Cabecera del } \\
\text { Guadalfeo }\end{array}$ \\
\hline 1956 & $\begin{array}{l}\text { Proyecto de Corrección y Repoblación de las Cuencas de la } \\
\text { Rambla la Garnatilla y Lagos (Y reformado parcial del proyecto en } \\
1967)\end{array}$ & $\begin{array}{l}\text { Cabecera del } \\
\text { Guadalfeo }\end{array}$ \\
\hline 1966 & $\begin{array}{l}\text { Proyecto de Corrección y Repoblación Forestal de la Cuenca del } \\
\text { barranco de Las Angosturas, afluente de la rambla de Albuñol } \\
\text { ynteproyecto de estabilización del suelo de la cuenca del Río Adra }\end{array}$ & $\begin{array}{l}\text { Vertientes al } \\
\text { mar }\end{array}$ \\
\hline 1977 & $\begin{array}{l}\text { Proyecto de Restauración Hidrológico-Forestal de la Cuenca de la } \\
\text { rambla de Albuñol }\end{array}$ & $\begin{array}{l}\text { Vertientes al } \\
\text { mar }\end{array}$ \\
\hline 1979 & $\begin{array}{l}\text { Proyecto de Restauración Hidrológico-Forestal del Pantano de } \\
\text { Béznar }\end{array}$ & $\begin{array}{l}\text { Cabecera del } \\
\text { Guadalfeo }\end{array}$ \\
\hline
\end{tabular}

Fuente: Evaluación sistemática de las acciones de repoblación forestal... LUCDEME 2.009 M. ${ }^{\circ}$ de Medio Ambiente, Rural y Marino

En ese contexto, destacan los trabajos amparados por la Conferencia de las Naciones Unidas sobre la desertificación celebrada en Nairobi (Kenia, 1977) y desarrollados desde entonces. La Revista «Papeles de Geografía», entre otras, recopiló las referencias bibliográficas sobre el problema de la erosión. Este trabajo divide la producción científica sobre la erosión en quince ámbitos, desde los estudios de carácter general hasta acciones de lucha contra la erosión, pasando por la erosionabilidad del suelo, la vegetación, el abandono de campos cultivados, etc-. Suman más de doscientos treinta artículos. Producción científica que nace a partir de 1.978, (Ver Papeles de Geografía núm. 32, 2.000). La respuesta de la Administración Forestal ante el problema de la erosión del suelo y sus repercusiones en la vegetación, estuvo marcada, además, por una importante producción legislativa destinada a poner remedio a esta situación, muy especialmente en aquellas zonas, como la Cuenca del Guadalfeo y la vertiente Surmediterránea que como se ha visto tenía una gran tradición en este tipo de actuaciones. Dada la limitación espacial no podemos entrar en ello aquí. Las Declaraciones de Repoblación Obligatoria suponían el cuerpo normativo en el que debían apoyarse las actuaciones a desarrollar en las zonas declaradas, pero además sería necesario elevar los proyectos de actuación. Con este objetivo, paralelo a la normativa se realizaron entre los años 1.932 y 1.979 diez y nueve proyectos de Restauración Hidrológica-Forestal (Cuadro 2) en otras tantas 
Cuencas Hidrográficas, coincidiendo en su mayoría con las zonas declaradas, aunque en algunos casos las Declaraciones no conllevaron aparejada actuación alguna, este sería el caso de Almuñécar y la cabecera del Río Adra, en la que se encuentra el embalse de Beninar, cuyas actuaciones debieron esperar y enmarcarse en otros proyectos aislados.

Como indicábamos anteriormente, tras la Conferencia de las Naciones Unidas sobre la desertificación celebrada en Nairobi (Kenia) en el año 1.977 en el que se elaboró el mapa mundial de los desiertos y de las áreas proclives a la desertificación, en el que España aparecía como el único país de Europa Occidental que incluía importantes zonas sometidas a importantes problemas de desertificación grave. El citado mapa presentaba todo el sureste español, principalmente en las provincias de Almería, Granada, Málaga, Murcia, Valencia, Alicante y Castellón, calificados de riesgo de desertificación muy alto, en comparación con otras zonas con riesgo moderado, como son el Valle del Ebro, la meseta central, Extremadura y Huelva. Tras la conferencia se estableció el Plan de Acción contra la desertificación (DESCON) que en España se tradujo en el Proyecto de Lucha contra la Desertificación en el Mediterráneo (LUCDEME) con el fin de atender las recomendaciones establecidas por el DESCON de naciones Unidas. Se incorpora el término «desertificación» primer país europeo que lo incorpora al ámbito institucional. Tras las transferencias a las Comunidades Autónomas, en materia medio-ambiental, concretamente a Andalucía, en el año 1.984 como se ha visto se crea el primer organismo con competencias en materia de medio ambiente en Andalucía, sin embargo, el problema de la desertificación ya había adquirido una importante dimensión, por lo que se mantendrá el «Proyecto LUCDEME» en vigor en las provincias de Almería, Granada y Málaga, permaneciendo en esta última provincia la sede del proyecto dentro del mermado organismo, ICONA como consecuencia de las referidas transferencias. El proyecto continua vigente en la actualidad ha reunido y generado una gran cantidad de información plasmada en estudios, evaluaciones, mapas temáticos, investigaciones, formulaciones y aplicaciones técnicas acerca del proceso de desertificación. En zonas áridas y semiáridas, en la provincia de Granada y Almería uno de los últimos trabajos publicados es la «Evaluación sistemática de los efectos sobre el suelo de las repoblaciones forestales para la lucha contra la desertificación en las cuencas del Adra y Guadalfeo (2.011)» (MAGRAMA, 2014).

De este provienen los espectaculares índices de vulnerabilidad de la cuenca media y alta (aguas arriba de la presa de Rules que recogemos en el cuadro 3 a modo de conclusión. 
Cuadro 3: Índices orientativos de la vulnerabilidad a la erosión

\begin{tabular}{|c|c|c|c|c|c|c|c|c|}
\hline $\begin{array}{l}\text { Cuenca } \\
\text { Basin }\end{array}$ & NOMBRE I NAME & $\mathbf{R}$ & Pc & Area/Tc & $\mathrm{K}$ & LS & c & P \\
\hline 1 & ALTO CADIAR & 212,51 & 37 & 26,60 & 0,11 & 8,76 & 0,06 & 1,00 \\
\hline 2 & BAJO CADIAR & 144,40 & 41 & 21,32 & 0,26 & 9,54 & 0,19 & 0,88 \\
\hline 3 & LOBRAS & 144,13 & 41 & 24,58 & 0,30 & 9,74 & 0,17 & 0,89 \\
\hline 4 & TORVIZCON & 131,85 & 47 & 22,30 & 0,33 & 11,40 & 0,28 & 0,96 \\
\hline 5 & ALCAZAR & 124,48 & 44 & 17,97 & 0,37 & 9,87 & 0,16 & 0,88 \\
\hline 6 & ALTO TREVELEZ & 228,88 & 42 & 37,68 & 0,11 & 10,33 & 0,08 & 1,00 \\
\hline 7 & BAJO TREVELEZ & 167,47 & 43 & 23,69 & 0,12 & 10,51 & 0,08 & 0,91 \\
\hline 8 & ALTO POQUEIRA & 231,77 & 45 & 43,34 & 0,11 & 11,30 & 0,08 & 1,00 \\
\hline 9 & BAJO POQUEIRA & 172,47 & 51 & 36,19 & 0,12 & 13,24 & 0,06 & 0,92 \\
\hline 10 & TABLONES & 118,85 & 41 & 18,76 & 0,29 & 9,00 & 0,11 & 0,91 \\
\hline 11 & SECO & 123,93 & 43 & 10,10 & 0,27 & 9,76 & 0,20 & 0,85 \\
\hline 12 & CASTILLEJOS & 136,24 & 53 & 9,99 & 0,24 & 12,81 & 0,06 & 0,94 \\
\hline 13 & CHICO & 184,54 & 38 & 15,24 & 0,16 & 8,78 & 0,11 & 0,92 \\
\hline 14 & SUCIO & 141,32 & 34 & 11,38 & 0,20 & 7,48 & 0,17 & 0,88 \\
\hline 15 & CHUCA & 100,80 & 30 & 18,89 & 0,31 & 6,04 & 0,19 & 0,87 \\
\hline 16 & TABLATE & 135,51 & 41 & 13,48 & 0,26 & 9,23 & 0,16 & 0,94 \\
\hline 17 & ZAZA & 125,20 & 45 & 12,55 & 0,24 & 10,77 & 0,17 & 1,00 \\
\hline 18 & LANJARON & 183,82 & 44 & 20,16 & 0,15 & 10,78 & 0,14 & 0,90 \\
\hline 19 & NEGRA & 129,65 & 43 & 6,87 & 0,21 & 9,82 & 0,07 & 0,99 \\
\hline 20 & CERRADA DE RULES & 98,19 & 35 & 11,51 & 0,36 & 7,42 & 0,25 & 0,96 \\
\hline
\end{tabular}

$\mathrm{R}=$ factor $\mathrm{R}$ de la U.S.L.E. (erosividad de la lluvia); $\mathrm{PC}=\mathrm{Pendiente}$ media, en \%; Area/TC= relación área/tiempo de concentración, en $\mathrm{km}^{2} / \mathrm{h}$; $\mathrm{K}=$ factor $\mathrm{K}$ de la U.S.L.E. (erosionabilidad del suelo, en T/ha.unidad de R); LS $=$ factor LS de la U.S.L.E. (factor de relieve o topográfico, en $\mathrm{km}$ ); $\mathrm{C}=$ factor $\mathrm{C}$ de la U.S.L.E. (factor de cubierta vegetal); $P=$ factor $P$ de la U.S.L.E. (factor de prácticas de conservación del suelo).

$R=R$ factor of the U.S.L.E. (erosivity of rain); $P C=$ Mean slope, in \%; Area/TC= relation arealtime of concentration, in $\mathrm{km}^{2} / \mathrm{h}$; $K=K$ factor of the U.S.L.E. (soil erodability, in T/hect. $R$ unit), $L S=L S$ factor of the U.S.L.E. (relief or topographic factor, in $\mathrm{km}$ ); $C=C$ factor of the U.S.L.E. (vegetation cover factor); $P=P$ factor of the U.S.L.E. (factor of soil conservation practices).

Fuente. MAGRAMA, 2014.

\section{CONCLUSIONES}

Aparte lo ya apuntado sobre las causas de los elevados valores erosivos y la extensión del riesgo grave de desertificación cabe concluir, mas en general, que todos los datos apuntan a un alto deterioro ambiental como consecuencia del uso no sostenible de la vegetación, que produjo en las cabeceras de las cuencas 
hidrográficas un alto grado de erosión y torrencialidad. Esta situación que venía produciéndose desde tiempo inmemorial se vio agravada a lo largo de los siglos XVIII-XIX coincidiendo con el periodo frío denominado «Pequeña Edad de Hielo» Sousa Martín, A. y García Murillo, P. (2005), Martín Vide, J. y Olcina Cantos, J. (2001), Geoffrey Parker, (2013) ${ }^{20}$ episodios en los que se sucedieron épocas especialmente lluviosas. Además de ello, el problema de la torrencialidad la gran deforestación que se produjo en este periodo fue como consecuencia de un crecimiento de la población y el consiguiente consumo de biomasa en forma de maderas, leñas y pastos para los ganados. Como también las sucesivas roturaciones producidas en los montes, especialmente los de titularidad pública que se vieron obligados a aceptar esta situación y a legitimar estas actuaciones por la presión de la población.

\section{BIBLIOGRAFÍA}

Abelló DE LA Torre, M. A.: (1988) Historia y evolución de las repoblaciones forestales en España. Tesis Doctoral, dirigida por Bosque Maurel, J. Madrid: Universidad Complutense de Madrid, 1988.

ANónimo: (1918) El problema forestal en la División Hidrológico-forestal del Guadalquivir. Revista Montes N. ${ }^{\circ} 102$.

Arriola Calleja, T. (1.955). La erosión del suelo español a través de la Legislación Forestal. Revista Montes N. ${ }^{\circ} 61$ Año 1955 páginas 19-26.

Artigas, P.: (1877) Inundaciones y repoblación de montañas. Traducción íntegra de un artículo relativo a la materia, y suscrito por el ingeniero forestal M. De la Grye. Revista Montes N. ${ }^{\circ} 18$ Volumen: I Año 1877. Páginas 418-425.

Capel Molina J.: (1974) Génesis de las inundaciones de octubre de 1973 en el sureste de la Península Ibérica. Cuadernos Geográficos de la Universidad de Granada $n .^{\circ}$ 4, 1974, pág. 149-166.

CARRERAS y RAMON, L.: (1802). Memoria presentada a la junta de reales obras de la ciudad de Málaga. Sobre los estragos que causa el rio de Guadalmedina á Málaga, y arbitrio para su remedio. Impresor de la Real Maestranza de caballería de Ronda.

Castillo Martín, A..» (1999) Agua y Acequias en la Alpujarra (Sierra Nevada)» II conferencia de La Alpujarra». Ed. Rosúa y Cátedra UNESCO. Pág. 151-164. 1999

CERón, S.: (1885) Breves apuntes. Estudio acerca de los perjuicios ocasionados en la riqueza agrícola y en la higiene de la provincia de Cádiz por la desaparición de las masas forestales en algunas zonas de la provincia. Análisis orográfico, climatológico

20. En cuanto a la «Pequeña Edad de Hielo» en este trabajo concretamente, se recogen episodios de cambios en el clima a nivel mundial, registrándose además de periodos fríos, otros de lluvias intensas durante periodos de tiempo muy largos en el siglo XVII, en toda Europa, concretamente «...Cataluña sufrió $<<$ lo any del diluvi $>>$ en 1617: tras un mes de continuas lluvias, un aguacero final de cuatro días causó inundaciones que arrasaron puentes, molinos, obras de drenaje, casas e incluso murallas de ciudades». 
y de vegetación. Causas y consecuencias de la desaparición de algunos montes. Revista Montes N. ${ }^{\circ}$ 201,202 Volumen: IX Año 1885. Páginas 257-262, 281-287.

Crespo Llanes, A.. (2000) El Control Jurídico de la erosión del suelo. La desertificación. Crespo Llanes, Andrés. Tesis doctoral de la Universidad de Alicante. 2.000

ICONA. (1990) Mapa de Estados erosivos. Cuenca Hidrográfica del Sur de España. Ministerio de Agricultura, Pesca y Alimentación. Introducción, página 7. Madrid, 1990.

Junta de Andalucía, Consejería de Medio Ambiente. (2015) Catálogo Nacional de Inundaciones Históricas. Aplicación informática desarrollada por la Dirección General de Protección Civil y Emergencias (DGPCE), Ministerio del Interior. Red de Información Ambiental. (REDIAM). Consejería de Medio Ambiente y Ordenación del Territorio. Junta de Andalucía.

Junta de Andalucía, Consejería de Medio Ambiente.: (2010) Estudio Piloto para la Gestión Integrada del Agua. Agencia Andaluza del Agua. 2010.

LaviÑA, F.: (1985) Conclusiones acordadas por el Congreso contra las inundaciones de Murcia. Revista Montes N. ${ }^{\circ} 198$ y 199 Volumen: IX Año 1885. Páginas 185-192

Martin-Mateo, R. (2000) Tratado de Derecho Ambiental -, vol. 1, Ed. Trivium, pág. 209. Tesis doctoral. Universidad de Alicante. 2.000

Martín Vide, J. y Olcina Cantos, J., (2001) Clima y tiempos en España. Alianza editorial.

Martínez Falero, J. (1950) Trabajos hidrológico-forestales realizados en la capital de Málaga para su defensa contra las inundaciones y daños producidos por los torrentes y ramblas. Revista Montes N. ${ }^{\circ} 33$. 1950. páginas 293-335.

Pardo, E. (1885) Congreso contra las inundaciones. Discurso pronunciado por D. Eduardo Pardo en la sesión del 21 de Marzo sobre el tema VII del Cuestionario. Revista Montes N. ${ }^{\circ} 199$ Volumen: IX Año 1885. Páginas 219-226.

Redacción de La Revista Montes: (1879) Las inundaciones de Murcia, Alicante y Almería. Revista Montes N. ${ }^{\circ} 67$ Volumen: III Año 1879 páginas 529-532.

Rodriguez MARTínez, F.: (1989) Estudio metodológico para la elaboración de una base documental y cartográfica sobre información hidrológica en Andalucía. Junta de Andalucía. Consejería de Obras Públicas y Transportes. CETU. Inédito. 1989

Rodriguez Martínez, F.: (2003). Los derrames penibéticos. Alteración regímenes fluviales peninsulares. 1901-2000. Pág. 131-170.

Rojo Serrano, L.. (1993) «Criterios para la determinación de objetivos protectores en la reforestación». Elección de especie y densidad de plantación. Revista Montes n. ${ }^{\circ}$ 33, páginas 116-121, 1993.

Sanchez Ramos, V.: (2010) «El Andarax, una singularidad del sureste». En Río Andarax, Página 13. Agencia Andaluza del Agua. Junta de Andalucía. 2010.

Sousa Martín, A. y García Murillo, P., Historia ecológica y evolución de las lagunas peridunares del parque Nacional de Doñana. Organismo Autónomo de Parques Nacionales. Ministerio de Medio Ambiente. 2005. 